\title{
EL VALOR DEL TIEMPO EN LAS EXPRESONES CONTRAFACTUALES*
}

\author{
Mabel Urrutia** \\ Manuel de Vega***
}

\section{Resumen}

Existen diversos recursos gramaticales para expresar el estatus de irrealidad de los contrafactuales, entre ellos, la selección del modo y del tiempo verbal. A su vez, distintas disciplinas han abordado el estudio formal de los contrafactuales, cuyos principales supuestos teóricos se discuten en este artículo. Específicamente, se analizan las expresiones contrafactuales prototípicas como "si me hubiera ganado la lotería, me hubiera comprado un Mercedes Benz" en comparación con otros tiempos verbales que expresan imposibilidad o probabilidad como es el caso de los prefactuales.

Palabras Claves: Contrafactual, Condicional, Prefactual, hipótesis de accesibilidad de la información.

\section{VALUE OF TIME IN COUNTERFACTUAL EXPRESSIONS}

\begin{abstract}
There are several grammatical resources to express unreality status of counterfactuals, including mode selection and the tense. In turn, different disciplines have studied the counterfactual expression, whose main theoretical assumptions are discussed in the current article. We analyze the prototypical counterfactual expressions like "If I had won the lottery, I would have bought a Mercedes Benz" in comparison with other tense forms that express impossibility or probability as in the case of prefactuals.
\end{abstract}

Key words: Counterfactual, Conditional, Prefactual, accessibility hypothesis of information.

* La presente investigación fue desarrollada en el marco del proyecto Neurocog de la Agencia Canaria ACIISI y el proyecto europeo FEDER. Cuenta con el apoyo del proyecto SEJ2004 del Ministerio de Ciencia de España.

** Chilena. Doctora en Lingüística de la Universidad de Concepción. Académica de la Universidad de Concepción, Concepción, Chile.maurrutia@udec.cl

Española. Doctora en Psicología de la Universidad de La Laguna. Investigadora de la Universidad de La Laguna, España. murrutia@ull.es.

*** Español. Doctor en Psicología de la Universidad de La Laguna. Catedrático de la Universidad de La Laguna, España.mdevega@ull.es 


\section{Estructuras contrafactuales: El "como si" de la realidad narrativa}

Desde una perspectiva lógica, las estructuras contrafactuales son un tipo de condicional compuesto por dos elementos: un antecedente y un consecuente ${ }^{1}$. El contenido lógico de un contrafactual es una doble negación implícita (no-p \& no-q). En efecto, para formar un contrafactual se niega de forma implícita tanto la condición antecedente como la consecuencia que se hubiera derivado de aquella. El consecuente describe la forma en que el mundo podría haber sido si el antecedente hubiera ocurrido, a través de un razonamiento causal directo entre estos dos elementos. Así en: "Si hubiera hecho buen tiempo (antecedente), habría ido a la playa a tomar sol (consecuente)" donde el consecuente depende del antecedente para que se cumpla. En el ejemplo: "tomar sol" sólo si hay "buen tiempo".

Desde un punto de vista lingüístico, una forma característica de expresar el contrafactual (aunque no la única) es emplear la conjunción condicional si, seguida de dos cláusulas (antecedente y consecuente), la primera de ellas obligatoriamente en modo subjuntivo (pretérito pluscuamperfecto). La fórmula prototípica de un contrafactual es, por tanto: "Si + pluscuamperfecto de subjuntivo + pluscuamperfecto de subjuntivo o condicional compuesto"2. Así, en el ejemplo anterior "Si hubiera hecho buen tiempo..." focaliza sobre ciertas condiciones alternativas y sus posibles resultados "habría ido a la playa a tomar sol.", tomando distancia de las condiciones reales. Gracias al elemento subordinante "si...", el verbo que sigue a esta estructura facilita al lector la creación de un estado del mundo alternativo al real, al que sigue una consecuencia también irreal. De allí que parece adecuado el apelativo de "representaciones epistémicas encapsuladas" para referirse a los elementos contrafactuales (De Vega, Urrutia y Riffo, 2007; De Vega y Urrutia, 2012).

Desde una perspectiva pragmática, el antecedente de un contrafactual niega la realidad. Por ejemplo en: "Si hubiera tenido tiempo (no tenía tiempo), habría adoptado un cachorro" (no adoptó al cachorro). La

1 También se le llama "prótasis" y "apódosis"; “p” y “q"; “condicionante” y “condicionado".

2 En un estudio normativo realizado con oraciones semillas del tipo "Si Alicia lo hubiera saludado en la calle...", los participantes completaron la oración en un 50\% con tiempo condicional compuesto y el otro $50 \%$ con tiempo pluscuamperfecto de subjuntivo. 
posibilidad de que hubiera ocurrido el primer evento en el pasado hubiera facilitado (hipotéticamente) la realización de su consecuente. Sin embargo, la negación implícita de la información del antecedente cancela la del consecuente, pues se trata de hechos que, pudiendo realizarse en un universo paralelo, en realidad no ocurrieron y nunca ocurrirán en este universo pragmático-discursivo. Se trata en todo caso de presuposiciones negativas que niegan tanto el antecedente como el consecuente de una oración (Lakoff, 1970) o sólo el antecedente como defienden algunos autores (Karttunen, 1971). Aunque en algunos casos la negación se focaliza en uno de los elementos, cambiando el rol de subordinante y subordinado en cuanto a la falsedad de los hechos se refiere, de igual modo ambos elementos lingüísticos reciben la negación directa o indirectamente. Ver algunos ejemplos con consecuente en tiempo pluscuamperfecto y otros en condicional compuesto:

(1) Si hubieras gastado el dinero a manos llenas, ahora tendrías que pedir un préstamo para pagar tus deudas.

(2) Si hubiera llegado a tiempo, hubiera sacado al niño del agua para aplicarle respiración artificial.

(3) Si la hubieran invitado a la fiesta, hubiera ido con su mejor vestido para conquistar a la audiencia.

Nótese que la diferencia en el caso (2) es sólo temporal en relación al caso 1, esto es, en todos los casos existen dos mundos. Un mundo real que coincide con la enunciación del hablante, en términos pragmáticos, y otro mundo hipotético que se crea en el mundo real en el momento de la enunciación lingüística, pero cuyas características no se corresponden con la realidad. En el caso (1) No gastó el dinero, por tanto el consecuente no ocurrió más que en un mundo hipotético y en el caso (2) el sujeto llegó al lugar de los hechos, pero el matiz está en que llegó tarde, por tanto su consecuente también es falso. El caso (3) muestra una acción que no se realizó (recibir una invitación), lo cual implica que la segunda acción tampoco ocurrió (ir a la fiesta). En el fondo, el contrafactual tiene una doble naturaleza semántica ya que, aun siendo una negación de ciertos estados del mundo (no-p \& no-q), invita al oyente/lector a imaginarse su realidad al menos momentáneamente (mundo alternativo: p \& q). (Urrutia y De Vega, 2012; Urrutia, de Vega y Bastiaansen, 2012). 
El centro deíctico ${ }^{3}$ de estas estructuras parece estar situado entre la realidad del hablante y el tiempo en que transcurre la acción. Las relaciones temporales básicas expresadas en el modo de la irrealidad por excelencia (pluscuamperfecto de subjuntivo) toman como punto de partida lo que Veiga (1996) ha llamado "anterioridad primaria". De acuerdo con esto, los hablantes usan modo subjuntivo cuando no desean pronunciar una proposición como factual o, más todavía, cuando parten de algún punto de vista individual de la realidad. Una especie creencia o presuposición subordinada, que traza una línea epistémica ubicada fuera del dominio del hablante, por tanto, la información que se entrega bajo la forma subjuntiva no es de alta relevancia y se va haciendo cada vez menos accesible.

Existe otro tipo de condicional irreal que se conforma también con un antecedente del modo subjuntivo, pero en tiempo imperfecto y con un consecuente en tiempo condicional, la diferencia está en que el tiempo de la enunciación ya no pertenece al pasado, sino al presente del habla, por ejemplo en:

(4) Si supiese la verdad, sería feliz.

(5) Si me ganara la lotería, me compraría un auto Mercedes Benz.

El antecedente (4) funciona como una especie de conjetura, mientras su consecuente (5) como una posibilidad a futuro. Autores como Byrne y Egan (2004) han llamado a estas estructuras "Condicionales Prefactuales", que actúan de manera muy similar a los condicionales de indicativo en tiempo futuro, esto es: (4') "Llego a saber la verdad" y "soy feliz" (5') "Me gano la lotería (mañana)" y "Me compro un auto Mercedes Benz (mañana)" y se diferencian de los contrafactuales en que no hay una representación de una posibilidad negativa, sino más bien una posibilidad simple del tipo "me gano la lotería" y "me compro un auto Mercedes Benz". La característica semántica de un prefactual se centra en la incertidumbre o la probabilidad, mientras el contrafactual en la irrealidad. Además, el contrafactual, según las autoras, posee un mecanismo cognitivo más complejo, pues requiere la representación de dos posibilidades:

3 El centro deíctico propiamente dicho está situado en el entorno sensorio-motor inmediato en que se producen los actos del habla en la interacción cara a cara entre interlocutores (v.g., Bühler, 1979 [1965]). Sin embargo, en los textos y en el discurso sobre contenidos aplazados existe también un "centro deíctico virtual", creado en la mente del lector gracias a ciertos indicios gramaticales para lograr representarse el referente (v.g., Duchan, Bruder, \& Hewitt, 1995). 
por un lado, la conjetura "Si me hubiera ganado la lotería, me hubiera comprado un auto Mercedes Benz" y, por otro, un hecho presupuesto "No me gané la lotería" y "No me compré un auto Mercedes Benz". En definitiva, las representaciones hechas a partir de los contrafactuales son mucho más ricas en cuanto a la capacidad de inferir un mayor número de posibilidades alternativas o, si se quiere, de mundos paralelos a la realidad (Urrutia et al., 2012).

El modo indicativo, en ciertos contextos, preferentemente en una modalidad oral, puede expresar un grado de irrealidad como ocurre con construcciones de indicativo en tiempo presente: "Si lo sé, no me presento al examen". Dichas oraciones hacen referencia a un tiempo pasado, a pesar de que el tiempo de la enunciación sea el presente, esto porque actúan en forma equivalente a los subjuntivos de tiempo pluscuamperfecto, en el ejemplo: "Si lo hubiera sabido, no me hubiera presentado al examen". El sentido de acción acabada en el pasado se desprende del contexto previo a la estructura contrafactual: "Las preguntas de desarrollo estaban tan difíciles que si lo sé, no me presento al examen".

Es común encontrar contrafactuales de indicativo en un registro del español oral coloquial. Por ejemplo, aparecen en fórmulas irónicas como: "Si ella es simpática, yo soy un payaso", "Si tú eres actriz, yo soy Penélope Cruz", cuya falsedad es evidente, pues a través de la negación indirecta de su consecuente ("Yo no soy un payaso" o "Yo no soy Penélope Cruz") se niega también su antecedente ("De ninguna forma, ella es simpática" y "obviamente tú no eres actriz famosa").

Otra posibilidad de formar contrafactuales de indicativo está en algunas frases hechas del tipo "Que venga Dios y lo vea", en que la negación explícita del consecuente "Dios no vendrá" da lugar a una negación de su antecedente "Si esto es una piscina ("esto no es una piscina") que venga Dios y lo vea". Lo mismo ocurre en la perífrasis verbal "llegar + infinitivo", aunque en este caso la irrealidad se expresa por medio de la falsedad de su antecedente "Si llego a estar yo allí ("no estaba alli") le canto 3 verdades a la cara" ("no le dije nada").

Estas frases se han lexicalizado con el tiempo llegando a denotar un contenido de imposibilidad implícito en la semántica de sus construcciones. En expresiones como "si lo sé no me asomo por aqui" hay una presuposición negativa inicial ("no lo he sabido") a la que se suma la posibilidad de "haber hecho otra cosa diferente a la que he hecho 
realmente". Un caso similar se presenta en construcciones como "Si no es porque..." donde el contenido focal está en el consecuente. Así en: "Si no es porque necesito el dinero, hoy mismo renuncio al trabajo", cuya interpretación negativa sigue un orden inverso "no renuncié al trabajo" y, posteriormente, "necesito el dinero". Nótese que a pesar de que superficialmente ambas oraciones están enunciadas en tiempo presente, en realidad, representan un tiempo pasado que no volverá. El antecedente de este tipo de expresiones se formula con una negación "si no es porque necesito el dinero" de la que se infiere posteriormente una afirmación "necesito el dinero". Aunque a simple vista parece una construcción artificial, este tipo de expresiones es de uso frecuente en el español de cualquier hablante (Montolío, 1999, p. 3673-3674).

Ahora bien, existen diferentes tipos de irrealidad que se configuran en mundos "accidentalmente contrafactuales" y "mundos esencialmente contrafactuales". En el primer caso, sólo unas pocas características difieren del mundo real, por ejemplo, "Si tuviera un martillo, habría colgado el cuadro en la pared", donde sólo se necesita un cambio de estado "tener un martillo" para que el protagonista realice la meta. Un cambio más profundo se necesitaría en el caso de un contrafactual en modo subjuntivo: "Si hubiera tenido un martillo, habría colgado el cuadro en la pared", debido a que, además del martillo, el protagonista necesita volver al tiempo en que necesitaba un martillo, pues no es suficiente con la posesión del instrumento como en el primer caso. Este tipo de contrafactual es distinto al llamado "esencialmente contrafactual", en que existe un mundo paralelo, donde las entidades del mundo actual incluyen propiedades nuevas o comportamientos nuevos. Por ejemplo en la aseveración "Si las sillas flotaran" se necesita un universo en que la cualidad de ser sillas, con las propiedades intrínsecas de una silla, esto es, que sirva para sentarse, que tenga 4 patas, que tenga un respaldo, además, tengan la propiedad de flotar.

Hay todavía una clase de contrafactuales en que no se mantendría ningún mundo más que mundos imposibles como sucede con expresiones como "Tanto si la tierra fuera redonda como cuadrada" o "Tanto si Pedro fuera hombre como mujer". Aquí ambos mundos coexisten en uno solo, por tanto ninguno de ellos llega a representarse completamente más que en un plano completamente irreal (Montolío, 1999). Sin embargo, en ambos ejemplos uno de los mundos es real (la tierra es redonda) y el otro 
imposible (la tierra es cuadrada). Aunque en el plano conjetural en el que se desarrolla este tipo de expresiones, las dos posibilidades se conciben como reales, basándose en la simulación. Este tipo de contrafactual, de carácter disyuntivo, se aleja de lo que conceptualmente entendemos por contrafactual en este artículo, a pesar que se utilizan con bastante regularidad en la investigación científica, en la elaboración de hipótesis.

\section{Grado de realidad e irrealidad en los modos verbales}

Frente a la trilogía de referencias lógicas de lo "necesario", lo "posible" y lo "imposible", se han ido acumulando nuevos tipos de predicados para referirse a la semántica del modo subjuntivo. Prejuicio, emoción, duda, incertidumbre, imposibilidad, negación, volición, deseo, persuasión, prohibición, expresiones impersonales son algunos de los diversos apelativos que se emplean para describir la referencia del modo subjuntivo. De acuerdo a la perspectiva gramatical, algunos aspectos se destacan más que otros. Por consiguiente, mientras gramáticos como E. Alarcos, S. Gili Gaya, García Calvo, G. Rojo, E. Martinell, Fernández Ramírez (ver Navas Ruiz, R., 1990) hablan de la "no-realidad" expresada en el modo subjuntivo frente a la "realidad" propia del modo indicativo; otros autores como Hernández (1984) se inclinan por la oposición subjetiva/objetiva para la oposición gramatical subjuntivo/indicativo. Más todavía, el Esbozo de la Real Academia Española aún no se inclina por un concepto específico, pues comienza recogiendo los criterios estructuralistas indicativo $=$ realidad $/$ subjuntivo + irrealidad para pasar a la idea tradicional del subjuntivo como acción dudosa y terminar con la idea de un subjuntivo optativo que expresa deseo, necesidad y voluntad.

A raíz de esta mezcla de significados, Hernández (1984) logró distinguir un tipo de modo subjuntivo de carácter dubitativo en el que se subdividen a su vez 3 tipos: duda, posibilidad e irrealidad. La aproximación semántica más fiel del contrafactual analizado aquí sería el modo marcado de la irrealidad en condicionales contrafactuales.

Por su parte, Alarcos Llorach (2001, p. 136) configura el significado del modo en 3 zonas diferenciadas por distintos significantes:

a) La de los hechos estimados reales o cuya realidad no se plantea por ser indiferente en la situación del hablante. 
b) La de los hechos cuya realidad es factible siempre que se cumplan ciertas condiciones (el paso del tiempo, el cambio de circunstancias $\mathrm{u}$ otros factores).

c) La de los hechos ficticios, cuya eventual realidad se ignora o cuya irrealidad se juzga evidente (hechos que se imaginan, se desean, se sospechan, etc.)

De lo anterior, el autor llega al planteamiento de 3 sistemas modales: indicativo, modo de la no-ficción; el condicionado, modo de lo posible y el subjuntivo, modo no-real.

La actuación en la estructura del sistema verbal español a partir de la oposición irreal/real no se da en forma pura como se ha visto anteriormente, puesto que en ciertos contextos sintácticos el modo indicativo expresa irrealidad y el subjuntivo, realidad. La manipulación de irrealidad depende de algunos factores sintácticos como el tiempo verbal de la acción expresada por el verbo y el uso de ciertas construcciones sintácticas de irrealidad como el condicional "si", adverbios como "quizás", "tal vez", factores contextuales como el plano de + irrealidad contribuyen a perfilar el grado de realidad o irrealidad en una estructura determinada.

Veiga (1996) manifiesta la superioridad jerárquica de algunos tiempos del subjuntivo que amplían las posibilidades de manifestación temporal irreal derivadas del empleo de ciertas construcciones verbales como las formas verbales cantara-se y hubiera-se cantado. El autor clasifica el modo subjuntivo en dos tipos: Subjuntivo 0 (SUBJ 0), por ejemplo: que haya cantado no es ninguna novedad; también que cantare o cantase y Subjuntivo 2 (SUBJ 2), e.g. que hubiera cantado no habría sido ninguna novedad. Con el término SUBJ 0 se refiere a la unidad modal subjuntiva y no irreal, mientras con el SUBJ 2 se refiere a la forma subjuntiva irreal por excelencia.

Este sistema contrasta con dos tipos de Indicativos: Indicativo 0 (IND 0), donde el valor del indicativo no añade ningún rasgo modal marcado, por ejemplo, he cantado porque me gusta y un Indicativo 2 (IND 2) que corresponde al indicativo irreal (objetivo), propio de las formas verbales condicionales, cuya futuridad relativa comparte algunos valores del subjuntivo, por ejemplo en habría cantado (Hernández, 1984). 
Tal cual lo plantea Veiga (1996), el contenido modal del SUBJ 2 es marcado como irreal frente al SUBJ 0, no irreal y doblemente marcado frente al IND 0. Ambos modos forman parte de dos extremos de un continuum que contraponen la realidad frente a la irrealidad. De este modo, el contrafactual prototípico sería aquel en que "el subjuntivo sólo se usa si el acontecimiento implícito en la condición está en contradicción con los hechos"' (Veiga, 1996, p. 20).

\section{Representación cognitiva de los contrafactuales. Hipótesis de accesibilidad de la información}

Desde la perspectiva de los espacios mentales aplicadas a los modos verbales, entendemos que cuando utilizamos el modo indicativo, dos espacios están en juego: el espacio base $\mathrm{B}$, punto de partida para otras construcciones cognitivas, y el espacio $\mathrm{R}$, que representa la realidad de la expresión lingüística y estaría en el foco de la representación cognitiva, dependiendo estrechamente del espacio base, pues está subordinado a éste. Ambos espacios son reales, de modo que cuando utilizamos el modo indicativo, partimos de un dominio base real y focalizamos en un espacio R, correspondiente a la realidad del hablante. Por tanto, en las construcciones factuales queda abierta la posibilidad de acceder a los elementos en R mediante sus homólogos en B. En el ejemplo "Como se acordó de apagar el móvil en el cine, disfrutó de la película sin interrupciones". La información en B ("se acordó de apagar el móvil en el cine...") fluye directamente a R (“... disfrutó de la película sin interrupciones").

El modo subjuntivo, en cambio, indica un cambio de perspectiva del espacio desde $\mathrm{R}$ (que expresa la realidad del hablante) a $\mathrm{M}$ (un espacio mental completamente hipotético), lo cual implica que los elementos en $\mathrm{M}$ no pueden ser accedidos mediante sus homólogos en $\mathrm{R}$, puesto que $\mathrm{M}$ es tanto el espacio foco como el punto de vista (Mejías-Bikandi, E., 1996, p. 158). El mismo ejemplo en una versión contrafactual: "Si se hubiera acordado de apagar el móvil en el cine, hubiera disfrutado de la película sin interrupciones" establece un espacio mental que no accede a la realidad "...disfrutar de la película sin interrupciones", pues se focaliza en la posibilidad que expresa su antecedente, esto es, un espacio mental que se traduce en una acción no realizada "no se acordó de apagar el móvil en el cine". En palabras de Fauconnier (1994, p. 109): "Lo contrafactual es un caso de incompatibilidad forzada entre espacios; un espacio M1 
es incompatible con otro espacio M2 si alguna relación explícitamente especificada en M1 no se satisface por los elementos correspondientes en $\mathrm{M} 2 "$ ".

Esto fue lo que algunos autores (Magliano y Schleich, 2000, Zwaan, Madden y Stanfield, 2001; Fauconnier, 1994) llamaron la hipótesis de accesibilidad, la cual predice que el modo subjuntivo cierra un espacio mental con su realidad correspondiente, haciéndolo menos accesible; en cambio, el modo indicativo, abre un espacio particular B, por tanto la información contenida en este espacio B pasa a un espacio más alto $(R)$ que, desde luego es más accesible.

Cuando un hablante utiliza el modo indicativo en un contexto particular, éste asume de algún modo la responsabilidad de lo que está diciendo, puesto que se siente más cercano al contenido de la proposición expresada por su cercanía al plano de lo real. En cambio, cuando un hablante utiliza el modo subjuntivo la información contenida en $\mathrm{M}$ no es accesible a $R$, pues existe una distancia mayor entre estos dos planos. Este salto cognitivo hace que el sujeto utilice una perspectiva epistémica divorciada del plano real, al operar dentro de un espacio mental hipotético o irreal.

Si se analizan estos supuestos a partir de algunas expresiones lingüísticas factuales, prefactuales y contrafactuales en modo indicativo y subjuntivo se tiene que en:

(6) "Como me gané la lotería, me compré un Mercedes Benz"

(7) "Si me hubiera ganado la lotería, me hubiera comprado un Mercedes Benz"

(8) "Si me ganara la lotería, me compraría un Mercedes Benz"

El flujo de información entre un espacio mental, configurado por el modo indicativo y la realidad, es directo, produciendo una simetría entre ambos planos, el espacio base y el espacio real (6). La construcción en modo subjuntivo, sin embargo, establece una condición que no ocurrió en el plano mental (si hubiera obtenido el premio) ni tampoco en el plano real (me hubiese comprado una casa), de allí la circularidad negativa en elementos lingüísticos como los contrafactuales (7). Los prefactuales, en cambio, siguiendo la lógica de Fauconnier (1994), acceden al plano real, a diferencia de lo que ocurre con los contrafactuales; pero lo hacen 
de una manera indirecta, pues el plano mental en subjuntivo hace que la información no acceda de una manera tan dinámica como la de los factuales, aunque finalmente una posibilidad P traspasa el universo del plano mental al real a través de la expresión en condicional ("se compraría un Mercedes Benz") y al menos una posibilidad P se activa en el plano real (8).

En definitiva, el modo es un marcador gramatical que indica el punto de vista actual respecto al contenido descrito, un mecanismo gramatical que regula la información compartida entre espacios mentales. No sólo eso, también puede ser considerado como una distinción gramatical entre dinámico y estático. Así, el modo indicativo es el modo de lo dinámico al crear contextos en que fluye la información desde el espacio mental a la realidad. En cambio, el subjuntivo es el modo de lo estático, pues marca un contexto particular estático que evita el flujo de información fuera del contexto del espacio mental epistémico. Es decir, que dicha representación epistémica está encapsulada, tal cual lo habíamos anunciado anteriormente (Mejías-Bikandi, 1996).

Si bien es cierto que la noción de accesibilidad explica la distinción semántica entre expresiones factuales (en indicativo) y contrafactuales (en subjuntivo), existen otras restricciones de carácter más pragmático que semántico, que dan cuenta de las diferencias entre ambos tipos de expresiones. Ya se ha dicho que la información en el modo subjuntivo permanece bloqueada en el espacio mental, mientras que en el modo indicativo hay una transferencia directa al espacio real. Esto no quiere decir que el modo subjuntivo sea un mecanismo gramatical per se que restrinja el flujo de información en el discurso, sino más bien una codificación gramatical del estatus pragmático de la proposición expresada por una cláusula determinada (Mejías-Bikandi, 2002).

Uno de estos factores pragmáticos es la idea de presuposición negativa asociada al modo subjuntivo en español. Así en un ejemplo como "Si le hubieran avisado del peligro, se hubiera apartado de la zona del derrumbe" hay una negación pragmáticamente presupuesta del tipo "no le avisaron del peligro" que representa una información conocida por el lector, el tema, por tanto la información que sigue se cancela en forma automática "no se apartó de la zona del derrumbe...". Nótese que el foco en esta oración está en el antecedente, la cláusula subordinante tiene un estatus cognitivo de baja activación. En el modo indicativo, en cambio, el mismo contenido 
de la oración implica una aserción pragmática que no se presupone, el rema, por tanto la información que contiene la oración es nueva para el lector: "Como le avisaron del peligro, se apartó de la zona del derrumbe". En el ejemplo, tanto el antecedente como el consecuente proporcionan información al lector, por tanto, ambos conceptos permanecen activos en la memoria al actualizarse la información que además es verdadera para el sujeto.

El tema y el rema están en función de un nuevo elemento en la representación discursiva que se extiende a las actitudes proposicionales o perspectiva epistémica del hablante: "No creo que", "creo que no" y "sé que no", en especial esta última que obliga a la introducción del modo subjuntivo en expresiones contrafactuales, ante la absoluta certeza de que los eventos no ocurrieron en el pasado. La postura epistémica de las expresiones factuales se opone a la anterior, pues conlleva la idea de aserción: "Sé que...", a diferencia de lo que ocurre en los prefactuales cuya actitud epistémico es neutral "Creo que...", puesto que, a diferencia de los contrafactuales, existe al menos una posibilidad de que los eventos lleguen a ocurrir en la realidad.

El modo verbal funciona también como marcador de la perspectiva epistémica, en cuanto señala el grado de certeza o de evidencia que el hablante atribuye al discurso. La sintaxis de los modos impone el esquema ideológico que cada hablante crea en su mente y expresa, a partir de su óptica mental, lo que algunos lingüistas como Molho llaman la "idea mirante".

En palabras de Molho, M. "La sintaxis de los modos es un problema de óptica mental [....] El juego sintáctico de los modos se reduce, pues, a una "dioptrique de la visèe" fundada en la consecución sistemática de los modos personales" (Molho, 1975, p. 363) Y luego: "La sintaxis modal no tiene más ley que la primacía de la idea mirante respecto de la mirada, que, cualquiera que sea, lleva resultativamente su marca" (Molho, 1975, p. 367).

Ahora bien, el modo verbal del español también da cuenta del grado de verosimilitud del pensamiento, distinguiendo entre un plano real, característico de los juicios factuales, plenamente verosímiles y un plano irreal, representado en verbos epistémicos (dudo que, imagino que, supongo que, etc.). La postura epistémica refleja la valoración del hablante sobre la relación entre el contenido de lo enunciado y la realidad. El 
contraste mayor se da entre el modo indicativo, el modo objetivo de la realidad $=$ verosimilitud y el subjuntivo, el modo no objetivo de la no realidad $=$ no verosimilitud (Kitova-Vasileva, 2000).

En definitiva, un espacio epistémico está configurado por un conjunto de valores de naturaleza escalar que revelan los distintos grados de compromiso del hablante con respecto a la factualidad de lo enunciado, esto es, en un estatus epistémico objetivo, la proximidad del sujeto frente a la situación real y al grado de factualidad de lo enunciado. En cambio, el estatus epistémico subjetivo da lugar a informaciones imprecisas de carácter personal en el que un sujeto puede moverse en dos subcampos modales: el de la probabilidad y el de la posibilidad, haciendo pronósticos futuristas, afirmaciones subjetivas, suposiciones infundadas, creando mundos imposibles, etc.

\section{Relativismo Lingüístico y Contrafactuales}

La complejidad de las estructuras contrafactuales conformadas por dos cláusulas con una relación condicional, más el uso del modo subjuntivo en tiempo pluscuamperfecto, podrían hacer pensar que los contrafactuales son elementos lingüísticos propios del español, pues la compleja conjugación del modo verbal en los distintos tiempos verbales es una característica diferencial del español. Sin embargo, en el inglés también existen elementos gramaticales distintivos para expresar el contrafactual en diferentes momentos de la enunciación. En el caso referencial de presente o futuro, el uso del verbo en pasado en la primera cláusula, seguida por el modal "would" o " $d$ " en la segunda cláusula, por ejemplo: "If she was to win first prize, the first thing that she would do was to buy a latest Mercedes car". Cuando el momento de enunciación se refiere al pasado, en la primera cláusula se usa el verbo en tiempo pasado perfecto y en la segunda, las formas "would have" o "might have". Por ejemplo: "If she had won the first prize, the first thing that she would have done were to buy a latest Mercedes car".

Estructuras equivalentes al español se utilizan en francés para expresar el contrafactual. Esta lengua romance está marcada por el imperfecto en la primera cláusula y el condicional en la segunda cuando el momento de la enunciación se refiere al presente y, en el pasado, el pluscuamperfecto en la primera cláusula y el pasado condicional en la segunda. En alemán, se utiliza el modo subjuntivo en ambas cláusulas y 
en mapudungum (lengua autóctona del sur de Chile) se utiliza también el modo subjuntivo para expresar las suposiciones (por ejemplo: "tripali" que significa "si salgo").

Al respecto, Bloom (1981, p. 14) argumenta que las estructuras específicas del lenguaje contrafactual tienen un impacto importante en la conceptualización y en el razonamiento. Bloom se apoya en la teoría del relativismo lingüístico de Sapir y Whorf (Whorf, 1971), cuyos supuestos fundamentales defienden la idea de que la cultura determina el lenguaje y éste, a su vez, determina la forma en que el ser humano conceptualiza la realidad. Bloom (1981) asegura que los hablantes del chino tienen dificultades para la comprensión de los contrafactuales y su uso es marginal respecto del inglés y otras lenguas indoeuropeas. De acuerdo a su hipótesis relativista, la lengua china no tiene una fórmula léxica, gramatical ni de entonación distintiva en el contrafactual y, en consecuencia, no cuenta con una herramienta lingüística específica para referirse explícitamente a eventos que no ocurrieron y que se expresan sólo con la finalidad de explorar lo que podría haber sido o lo que sería (Bloom, 1981, p. 16). Según el autor, la interpretación de los contrafactuales en chino depende del contexto inmediato del habla, mientras en inglés esto es menos frecuente, dado que la lengua posee marcadores más explícitos, frases hechas del tipo "If only" o "Might have been" son un ejemplo de ello. Bloom concluye, en definitiva, que la lengua china tiene un déficit estructural que conlleva dificultades en la configuración del pensamiento contrafactual en el hablante del chino.

Sin embargo, el autor se apoya en experiencias anecdóticas y algunos experimentos para llegar a dichas conclusiones. En diversas entrevistas, realizadas a hablantes del chino, recoge las reflexiones que los participantes realizan respecto de su confusión en la comprensión de los contrafactuales y la idea de que no existe en chino una expresión determinada para expresar un pensamiento hipotético de situaciones que nunca se llevaron a cabo, asimismo, destaca las características factuales dominantes de la lengua china. En la fase experimental, Bloom realizó varios test experimentales. En la primera tarea, elaboró tres versiones de una historia construida con contrafactual ${ }^{4}$ tanto para el chino como para

4 El esquema lógico para el inglés era: " $\mathrm{X}$ no es el caso, pero si $\mathrm{X}$ hubiera sido el caso, entonces $\mathrm{Y}$ podría haber sido el caso, entonces $\mathrm{Y}$ podría haber sido el caso, $\mathrm{Z}$ podría haber sido el caso y W podría haber sido el caso". Para el chino, "X no fue el caso, pero si $X$ fuera, entonces $Y$, entonces $Z$, entonces W" (Bloom, 1981, p.22). 
el inglés y luego les preguntaba a los participantes sobre el contenido de la historia. En concreto, preguntaba en forma directa o indirecta si los sujetos interpretaban bien el consecuente final de una serie de implicaciones referidas a cosas que habían sucedido o bien situaciones que no habían ocurrido en las historias.

El objetivo de la investigación consistía en evaluar si un hablante chino era capaz de dar una interpretación contrafactual a un párrafo que expresa un argumento contrafactual abstracto y complejo. Su hipótesis era que habría una diferencia significativa entre los hablantes del inglés y los chinos, estos últimos tendrían serias dificultades para comprender textos contrafactuales. Sus resultados apoyaron sus hipótesis, puesto que los hablantes del inglés mostraron una superioridad estadísticamente significativa frente a los hablantes monolingües del chino, en cuanto a que fueron capaces de interpretar perfectamente la simulación contrafactual. En cambio, los chinos, divididos en monolingües y bilingües, tuvieron un comportamiento deficiente en la comprensión de los contrafactuales, aunque los participantes bilingües actuaron de mejor forma que los hablantes monolingües, especialmente en las versiones en inglés de las historias.

Éste y otros nuevos experimentos llevaron al autor a concluir que la falta de distinción entre contrafactuales y oraciones implicativas se debe a la dificultad del chino para construir nuevos esquemas cognitivos en la discriminación de las formas lógicas: "Si entonces", "Si y sólo si entonces" y "Sólo si entonces". Según el autor, un hablante chino no es capaz de diseñar esquemas cognitivos específicos para el contrafactual, para proyectar y operar con inferencias teóricas a partir de los modelos de línea base que proporciona la realidad (Bloom, 1981, p. 34).

No obstante lo anterior, la diferencia de actuación de los hablantes chinos bilingües frente a los monolingües llevó al autor a pensar en una posible influencia de la cultura sobre el lenguaje, esto es, que el rechazo del pensamiento contrafactual por parte de los chinos se deba más bien a la historia de la sociedad en la que se desenvuelve el chino más que a influencias de la estructura lingüística de la lengua china, puesto que un hablante chino bilingüe con adiestramiento en la lengua inglesa es capaz de reconocer perfectamente la construcción gramatical del contrafactual al estar expuesto a esa lengua por más tiempo que un hablante monolingüe. 
Por esta vía comienzan a acentuarse las primeras críticas al trabajo de Bloom. La investigadora Au (ver Lucy, 1992) es una de las principales detractoras de los supuestos y consiguientes resultados de Bloom, cuestionando en primer término la falta de una base comparativa al establecer la deficiencia lingüística del chino frente al inglés, la supremacía de una estructura gramatical y su uso en un modo de discurso especializado y las dificultades para demostrar efectos no-lingüísticos a partir de estímulos meramente lingüísticos (Lucy, 1992). En el plano experimental, $\mathrm{Au}$ detectó un problema clave de tipo idiomático en la traducción de las frases al chino, pues éstas fueron bastante artificiales en el experimento de Bloom y, por tanto, difíciles de interpretar. Por otro lado, los estímulos experimentales no estaban contrabalanceados, pues el autor presentó todas las versiones del chino antes que las historias en inglés, lo cual puede haber afectado la respuesta de los sujetos en la tarea por un mero efecto de repetición de la exposición.

Au realizó varios estudios aplicando un diseño "experimental" y no cuasi-experimental como el de Bloom. Su hipótesis planteaba que las diferencias en la forma y sistematicidad de los marcadores lingüísticos de los contrafactuales afectan la habilidad para adoptar y sostener un punto de vista contrafactual de manera efectiva, debido, por una parte, a la ausencia de una construcción lingüística para el contrafactual en la lengua china y, por otra, a la sobrecarga de la memoria por el número de implicaciones contrafactuales y el número de claves contrafactuales en las historias de Bloom.

Au creó nuevas historias contrafactuales, haciendo una corrección idiomática a las historias de Bloom. Sus resultados difieren completamente de los estudios de Bloom, puesto que ella concluyó que los sujetos chinos bilingües tuvieron sólo pequeñas dificultades para entender las historias contrafactuales tanto en inglés como en chino. Sin embargo, se le ha criticado a $\mathrm{Au}$ que sus historias ${ }^{5}$ fueron de muy fácil interpretación, provocando un "efecto techo" en los resultados del experimento.

Las historias fueron más simples en términos estructurales y de complejidad del contrafactual y las preguntas se ciñeron más a hechos

5 La estructura lógica de las historias de Au para el chino fue la siguiente: “ $\mathrm{X}$ no entendió la lengua hablada por los nativos, si X hubiera sido capaz de entender la lengua hablada por los nativos y no huir de ellos, X habría aprendido Y. Indicar qué cosas (por ejemplo Ys) X sabe acerca de los nativos" (Lucy, 1992, p. 220). 
reales no conocidos que a eventos falsos inexistentes. Por este motivo, $\mathrm{Au}$ replicó el segundo experimento de Bloom (1981) y sus resultados tampoco se repitieron en relación con el autor, pues encontró que los rendimientos del investigador fueron significativamente más bajos que los suyos y además no encontró ninguna diferencia significativa entre los hablantes chinos bilingües y los monolingües.

Nuevas críticas al trabajo de Au fueron realizados por Bloom (1981) en una contrarréplica en relación con aspectos procedimentales del experimento como la heterogeneidad de la población, historias con menos contenido contrafactual, etc. Lo cierto es que, coincidiendo con Bloom en que cada lengua cuenta con dispositivos particulares gramaticales, léxicos, pragmáticos e incluso fonéticos en la expresión de un contrafactual, la capacidad para pensar en contrafactual, de proporcionar alternativas a la realidad circundante, de expresar emociones sociales básicas como el arrepentimiento, parece ser universal a través de las culturas. La problemática debiera más bien dirigirse al uso del contrafactual en la vida diaria, a la presencia de la necesidad funcional, en lugar de los mecanismos estructurales opcionales que lo configuran.

\section{Conclusiones}

En conclusión, lejos de limitar el estudio de los contrafactuales al campo de la gramática, estas construcciones del lenguaje se destacan por ser un mecanismo cognitivo fundamental para expresar un grado de irrealidad o inverosimilitud de los eventos representados en la realidad del hablante. Como hemos visto en este artículo, la selección del modo es una de las variables para la construcción del contrafactual, no la única, pues hay muchos elementos pragmáticos que se conjugan a la hora de expresar contrafactualidad, asimismo, las variables lingüísticas van cambiando de una lengua a otra, a favor de un sustrato cognitivo subyacente en este tipo de expresiones. La función del contrafactual es fundamental para la articulación del pensamiento, tanto en el orden lógico causal, en el razonamiento hipotético, como en el emocional para expresar emociones complejas como la culpa, el lamento, la frustración y, desde un punto de vista cognitivo, concebir nuevos escenarios en que las cosas podrían haber sido. 


\section{Bibliografía}

Alarcos Llorach, E. (2001). Gramática de la lengua española. Madrid: Espasa Calpe.

Bloom, A. (1981). The linguistic shaping of thought. A study in the impact of language on thinking in china and the west. New Jersey: Lawrence Erlbaum Associates, Publishers.

Bühler, K. (1979) [1965]. Teoría del lenguaje. Madrid: Alianza Universidad. Byrne, R. y Egan, S. (2004). Counterfactual and prefactual conditionals. Canadian Journal of Experimental Psychology, 58, 1131.

De Vega, M., Urrutia, M. y Riffo, B. (2007). Cancelling updating in the comprehension of counterfactuals embedded in narratives. Memory \& Cognition. 35(6), 1410-1421.

De Vega, M. y Urrutia, M. (2012). Discourse updating in texts with a counterfactual event. Psicológica, 33, 157-173.

Duchan, J., Bruder, G. y Hewithh, L. (1995). Deixis in narrative. A cognitive science perspective. Hillsdale:New Yersey. Erlbaum.

Fauconnier, G. (1994). Mental spaces. Aspects of meaning construction in natural language. New York: Cambridge University Press.

Hernández, C. (1984). Gramática funcional del español. Madrid: Gredos.

Karttunen, L. (1971). Implicative Verbs. Language, 47, 340-358.

Kitova-Vasileva, M. (2000). La 'verosimilitud relativa' y su expresión en español. Lucus Lingua, anexos de Moenia. Revista lucense de lingüística \& literatura, 8, 1-190.

Lakoff, G. (1970). Linguistics and natural logic. Synthese, 22, 151-257.

Lucy, J. (1992). Language diversity and thought. A reformulation of the linguistic relativity hypothesis. New York: Cambridge University Press.

Magliano, J. y Schleich, M. (2000). Verb aspect and situation models. Discourse Processes, 29(2), 83-112. 
Mejías-Bikandi, E. (1996). Space accessibility and mood in Spanish. En G. Fauconnier y E. Sweetser (Eds.), Spaces worlds and grammar (pp. 157-178). Chicago: The University of Chicago Press.

Mejías-Bikandi, E. (2002). Space accessibility and the pragmatic status of propositions. En J. Gutiérrez-Rexach (Ed.). From words to discourse: Trends in spanish semantics and pragmatics (pp. 145-158). Oxford: Elsevier.

Montolío, E. (1999). Las construcciones condicionales. En I. Bosque y V. Demonte (Eds.). Gramática descriptiva de la lengua española (pp. 3643-3747). Madrid: Espasa Calpe, S. A.

Molho, M. (1975). Sistemática del verbo español. Aspectos, modos, tiempos. Madrid: Gredos.

Navas Ruiz, R. (1990). El subjuntivo castellano. Teoría y bibliografía crítica. En I. Bosque (Ed.). Indicativo y subjuntivo (pp. 107-141). Madrid: Taurus Universitaria.

Urrutia, M., De Vega, M. y Bastiaansen, M. (2012). Understanding counterfactuals in discourse modulates ERP and oscillatory gamma rhythms in the EEG. Brain Research, 1455, 40-55.

Urrutia, M. y De Vega, M. (2012). Aproximación a la semántica del contrafactual, Estudios Filológicos, 49, 157-173.

Veiga Rodríguez, A. (1996). Subjuntivo, irrealidad y oposiciones temporales en español. En G. Wotjak (Ed.). El verbo español. Aspectos morfosintácticos, sociolingüísticos y lexicogenéticos (pp. 41-60). Madrid: Iberoamericana.

Zwaan, R., Madden, C. y Stanfield, R. (2001). Time in narrative comprehension: a cognitive perspective. En D. Schram y G. Steen (Eds.) Psychology and Sociology of literature (pp. 71-86). Amsterdam: John Benjamins.

Whorf, B. L. (1971). Lenguaje, Pensamiento y Realidad. Barcelona: Barral Editores. 